\title{
Quiz
}

Long-term unexpected single polyprolene suture complication following traditional pubovaginal sling: Suprapubic skin fistula

Sarıkaya and Huri. Suprapubic skin fistula

Selçuk Sarıkaya ${ }^{1}$, Emre Huri² $^{2}$

${ }^{1}$ Clinic of Urology, University of Health Sciences, Gülhane Research and Training Hospital, Ankara, Turkey ${ }^{2}$ Department of Urology, Hacettepe University Faculty of Medicine, Ankara, Turkey

Adress for Correspondence: Selçuk Sarıkaya

Phone: +90 5316274819 e-mail: drselcuksarikaya@hotmail.com ORCID ID: orcid.org/

\section{DOI: 10.4274/jtgga.2018.0149}

What is your diagnosis?

53 year-old female patient admitted to Hacettepe University, Faculty of Medicine/Department of Urology outpatient clinic with dysuria, swelling in the left inguinal region and severe urinary incontinence complaints. Informed consent was gained from the patient before this study. The patient had stress type urinary incontinence and had a history of midurethral sling operation 10 years ago due to her complaints. Incontinence complaints reduced in postoperative first three months but there was a recurrence afterwards. Patient had hypertension but no other comorbidities. According to the physical examination, there was Grade 1 -II cystocele and vaginal atrophy. Stress Bonney test was positive and there was erosion in left inguinal region due to the previous sling operation. Ultrasonography revealed abscess formation and mesh erosion in the left inguinal region. There were same findings with the computerised tomography. Afterwards cystometry was performed; the maximum vesical capacity was $637 \mathrm{ml}$ and the maximum vesical pressure was $33 \mathrm{cmH} 2 \mathrm{O}$. Simultaneously cystography revealed urine leakage while standing and there were no trabeculations. Uroflowmetry result was normal and there was no residual volüme. The abscess formation was thought to be as a result of the mesh inflammation. Mesh excision, abscess drainage and fascial transobturator sling operation was planned for the patient. During the operation aprroximately $4 \mathrm{~cm}$-diameter mass due to mesh inflammation was excised from the left inguinal region reaching to the retropubic area(Figure).

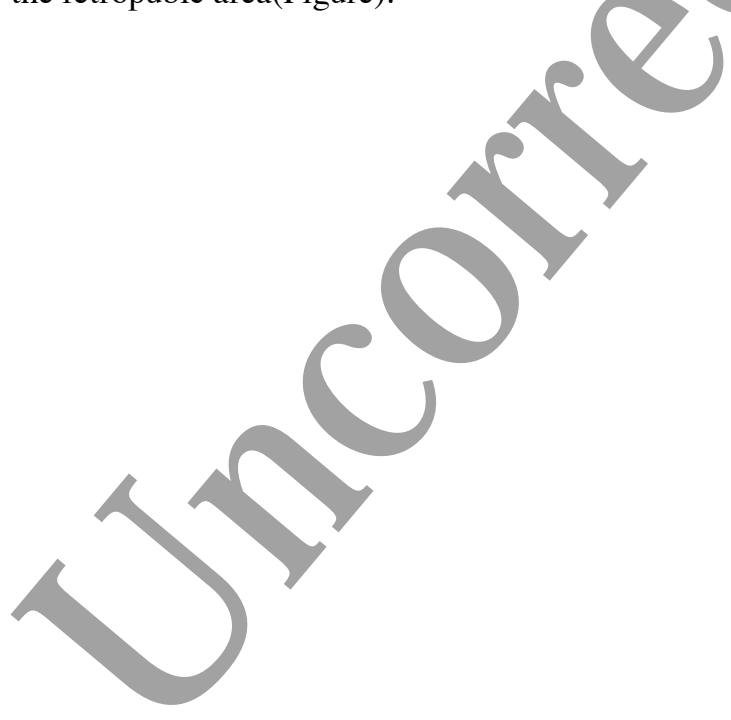




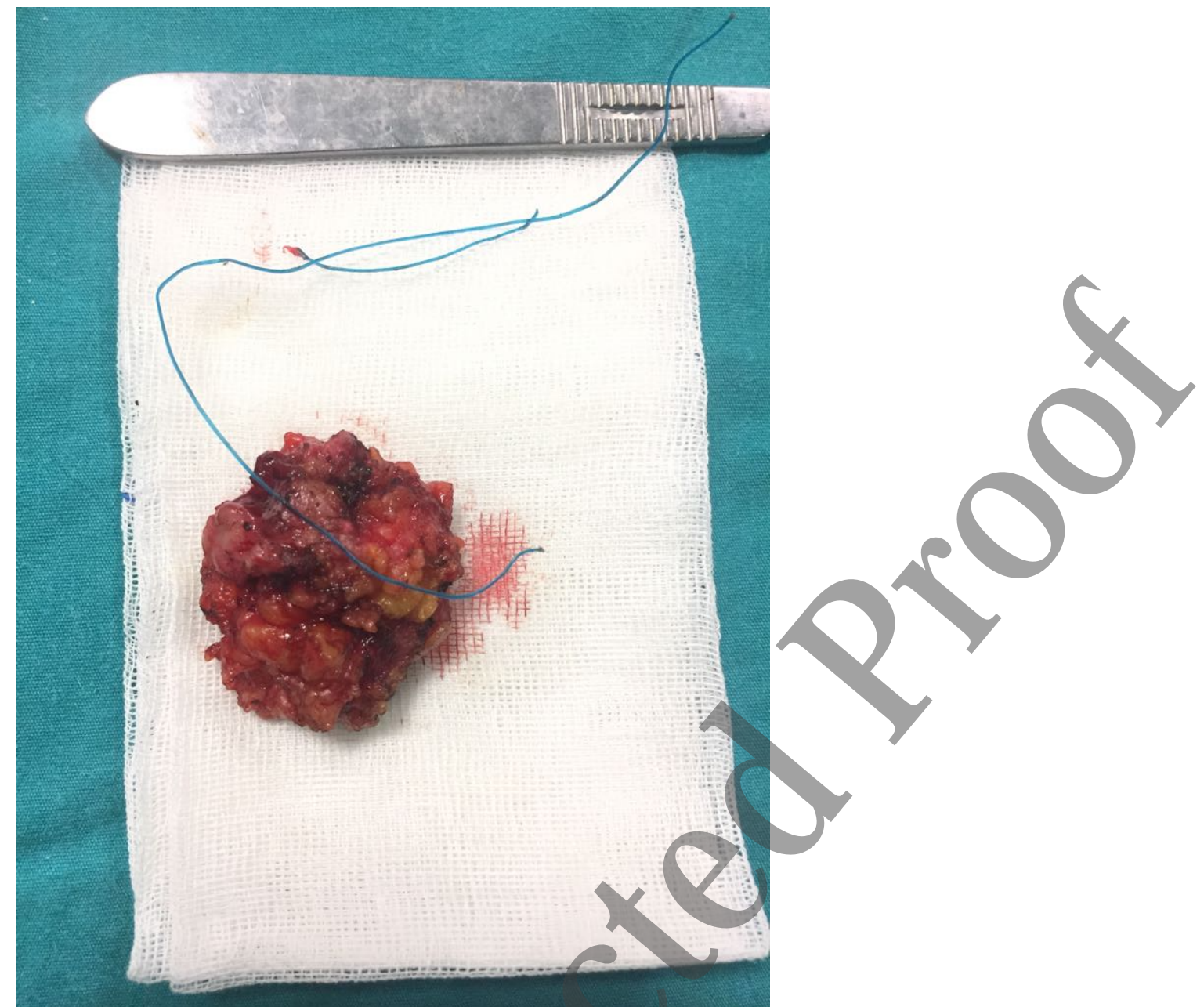

Figure: Macroscopic view of the abscess formation that was excised

\section{Answer}

Stress urinary incontinence is a commonly seen pathologic entity with $13 \%$ rate among women aged 19-44 years and $22 \%$ rate among women aged $45-64$ years. $(1,2)$ Unfortunately it is an underdiagnosed and underreported medical problem. Stress urinary incontinence can be assessed with physical examination, leak abdominal pressure point and some tests. Patients must undergo basic evaluation with voiding diary, cotton swab test, cough stress test, cystoscopy, postvoiding residual volume and urodynamic studies. There are lots of treatment methods that are used for the treatment of patients with stress urinary incontinence. Basically these methods would be divided into surgical and nonsurgical modalities. Duloxetine is a recent treatment choice as a medical treatment option and studies shown it's positive effects for the treatment. (3) Physical exercises also have positive effects and must be considered as a treatment option. Apart from these treatment modalities, surgery is also widely used in the treatment of stress urinary incontinence. (4) Pubovaginal sling is a commonly used surgical procedure as it has many advantages. This procedure has an excellent overall success and it is a good option with longer curative rates. (5) Midurethral sling is used more often than pubovaginal sling recently with good success rates as it has become the gold standart fort he treatment of stress urinary incontinence. $(5,6)$ Despite the positive outcomes sometimes there would be complications regarding this procedure. Infection, abscess formation would be seen as serious complications. Sometimes these complications would be corrected via excision of mesh.

\section{References}

1. Unger CA, Rizzo AE, Ridgeway B. Indications and risk factors for midurethral sling revision. Int Urogynecol J. 2016;27(1):117-22.

2. Shamliyan T, Wyman J, Bliss DZ, Kane RL, Wilt TJ. Prevention of urinary and fecal incontinence in adults. Evid Rep Technol Assess (Full Rep). 2007(161):1-379.

3. Caruso DJ, Gomez CS, Gousse AE. Medical management of stress urinary incontinence: is there a future? Curr Urol Rep. 2009;10(5):401-7. 
4. Shamout S, Campeau L. Stress urinary incontinence in women: Current and emerging therapeutic options. Can Urol Assoc J. 2017;11(6Supp12):S155-S8.

5. Bailly GG, Carlson KV. The pubovaginal sling: Reintroducing an old friend. Can Urol Assoc J. 2017;11(6Suppl2):S147-S51.

6. Punjani N, Winick-Ng J, Welk B. Postoperative Urinary Retention and Urinary Tract Infections Predict Midurethral Sling Mesh Complications. Urology. 2017;99:42-8.

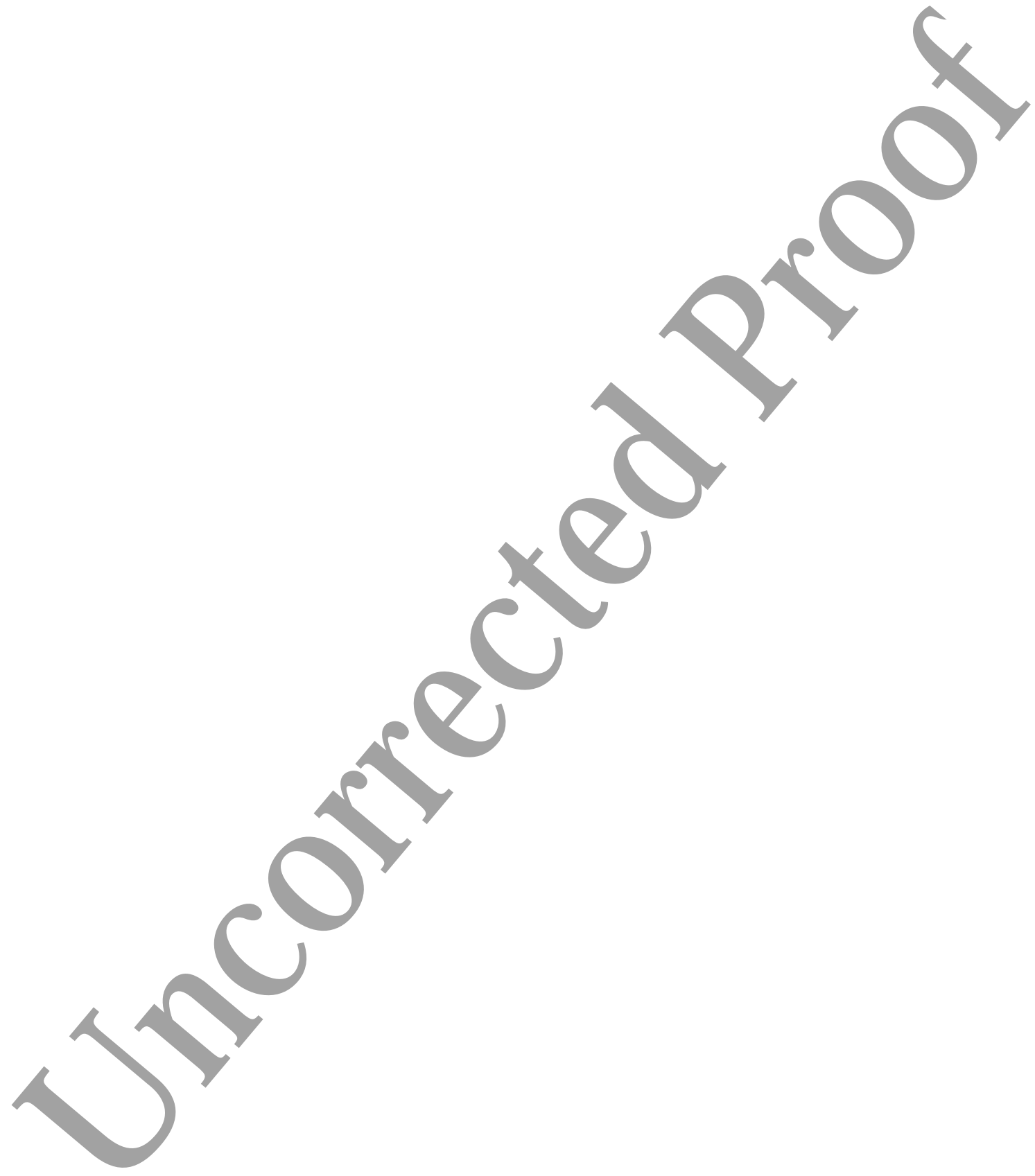

